\title{
Right-Sided Acute Diverticulitis in the West: Experience at an University Hospital in Argentina
}

\author{
René M. Palacios Huatuco, Diana A. Pantoja Pachajoa, Julian E. Liaño, Héctor A. Picón Molina, \\ Rafael Palencia, Alejandro M. Doniquian, Matías Parodi \\ General Surgery Service, Clínica Universitaria Reina Fabiola, Universidad Católica de Córdoba, Córdoba, Argentina
}

Purpose: In the West, diverticular disease is located mainly in the left colon. However, it can also present in the right colon, with an incidence of $1 \%-2 \%$ in Caucasians. The purpose of this study was to describe our experience in right-sided acute diverticulitis (RD).

Methods: In this retrospective study, 410 patients with acute diverticulitis treated from 2013 to 2020 were included in a university hospital in Córdoba, Argentina. Colonic diverticulitis was stratified into 2 groups; RD and left-sided acute diverticulitis. Demographic and clinical variables, laboratory and imaging findings, type of treatment, follow-up, and recurrence were analyzed.

Results: Sixteen patients (3.9\%) with RD were identified; $62.5 \%$ were male and the mean age was $40.7 \pm 11.7$ years. A total of $81.3 \%$ were Caucasian and $18.7 \%$ Native American. Significant differences were found between both groups of diverticulitis; patients with $\mathrm{RD}$ were younger $(\mathrm{P}=0.001)$, with lower $\mathrm{BMI}(\mathrm{P}=0.01)$, comorbidity rate $(\mathrm{P}=0.01)$, Charlson comorbidity index $(\mathrm{P}=0.02)$, hospital stay $(\mathrm{P}=0.01)$, severity according to the Hinchey classification $(\mathrm{P}=0.001)$ and had a lower recurrence rate $(\mathrm{P}=0.001)$. There were no significant differences in $\operatorname{sex}(\mathrm{P}=0.95)$, duration of pain until admission $(\mathrm{P}=0.05)$, laboratory findings $(\mathrm{P}=0.23)$ and treatment $(\mathrm{P}=0.34)$.

Conclusion: Conservative treatment predominated in $\mathrm{RD}$, with a lower rate of complications and recurrences, providing data that support conservative therapy as initial treatment in $\mathrm{RD}$ in our environment.

Keywords: Colonic diverticulitis; Hepatic flexure; Conservative treatment; South America; Neutrophil-to-lymphocyte ratio

\section{INTRODUCTION}

Diverticular disease (DD) has long been considered a common disease in Western countries. Worldwide, the major incidence is found in the United States, Europe, and Australia, affecting 50\% of the population over the age of 60 years, with a prevalence of $15 \%$ to $35 \%$ [1]. The lifetime risk of acute diverticulitis in someone with diverticulosis is $10 \%$ to $25 \%$ [2].

Received: Jun 1, 2021 - Revised: Aug 20, 2021 - Accepted: Aug 26, 2021 Correspondence to: René M. Palacios Huatuco, M.D.

General Surgery Service, Clínica Universitaria Reina Fabiola, Universidad Católica de Córdoba, Oncativo 1248, Córdoba X5004 FHP, Argentina

Tel/Fax: +54-351-4142121

E-mail: manuelpalacioshuatuco@gmail.com

ORCID: https://orcid.org/0000-0003-1863-7897

(C) 2021 The Korean Society of Coloproctology

This is an open-access article distributed under the terms of the Creative Commons Attribution NonCommercial License (https://creativecommons.org/licenses/by-nc/4.0) which permits unrestricted noncommercial use, distribution, and reproduction in any medium, provided the original work is properly cited.
Diverticulitis is a heterogeneous disease in both presentation and prognosis. Uncomplicated diverticulitis is the most common presentation and is characterized by acute onset of diverticular inflammation without abscess or perforation [3]. Among gastrointestinal diseases, is a leading cause of ambulatory visits, hospital admissions, and colon surgery, accounting for substantial healthcare expenditures [4].

Besides the geographical variability in the prevalence of $\mathrm{DD}$, there is significant variability in the location of colonic diverticula in different regions of the world [5]. According to reports in the west, it affects primarily the left side (90\%) predominating in the sigmoid colon, whereas in Asia it mostly affects the right-sided colon $(80 \%)$ with a prevalence of $8 \%$ to $25 \%$ [6, 7]. However, with increasing migration, it has recently been detected a major frequency of right-sided DD in the West [8]. These differences suggest that the pathophysiology of DD may differ between populations.

In the past decade, our understanding of diverticulitis has ex- 
panded substantially with the publication of multiple observational studies and clinical trials. Historically, diverticulitis was thought to be an aggressive disease, and the threshold for surgical intervention was low. With a better understanding of prognosis, a shift toward nonoperative approaches has occurred [3].

The purpose of this study was to describe our experience in right-sided acute diverticulitis, carried out in a Western university hospital.

\section{METHODS}

\section{Population and study design}

A retrospective cohort study was performed, which included all patients aged $\geq 18$ years with a diagnosis of acute diverticulitis treated from January 2013 to January 2020 at a University Hospital in Córdoba, Argentina. The information of the patients was collected through the review of medical records and an electronic database of the General Surgery Service. The colonic diverticulitis was stratified into 2 groups, according to the location of the diverticula: right-sided diverticulitis (RD) and left-sided diverticulitis (LD). The patients with DD associated with neoplasia and those with incomplete information in the electronic medical records were excluded.

This study was conducted in accordance with the Declaration of Helsinki of 1964 (revised in 2013) and was approved by the Institutional Ethics Committee of the Clinica Universitaria Reina Fabiola (No. 2021-017).

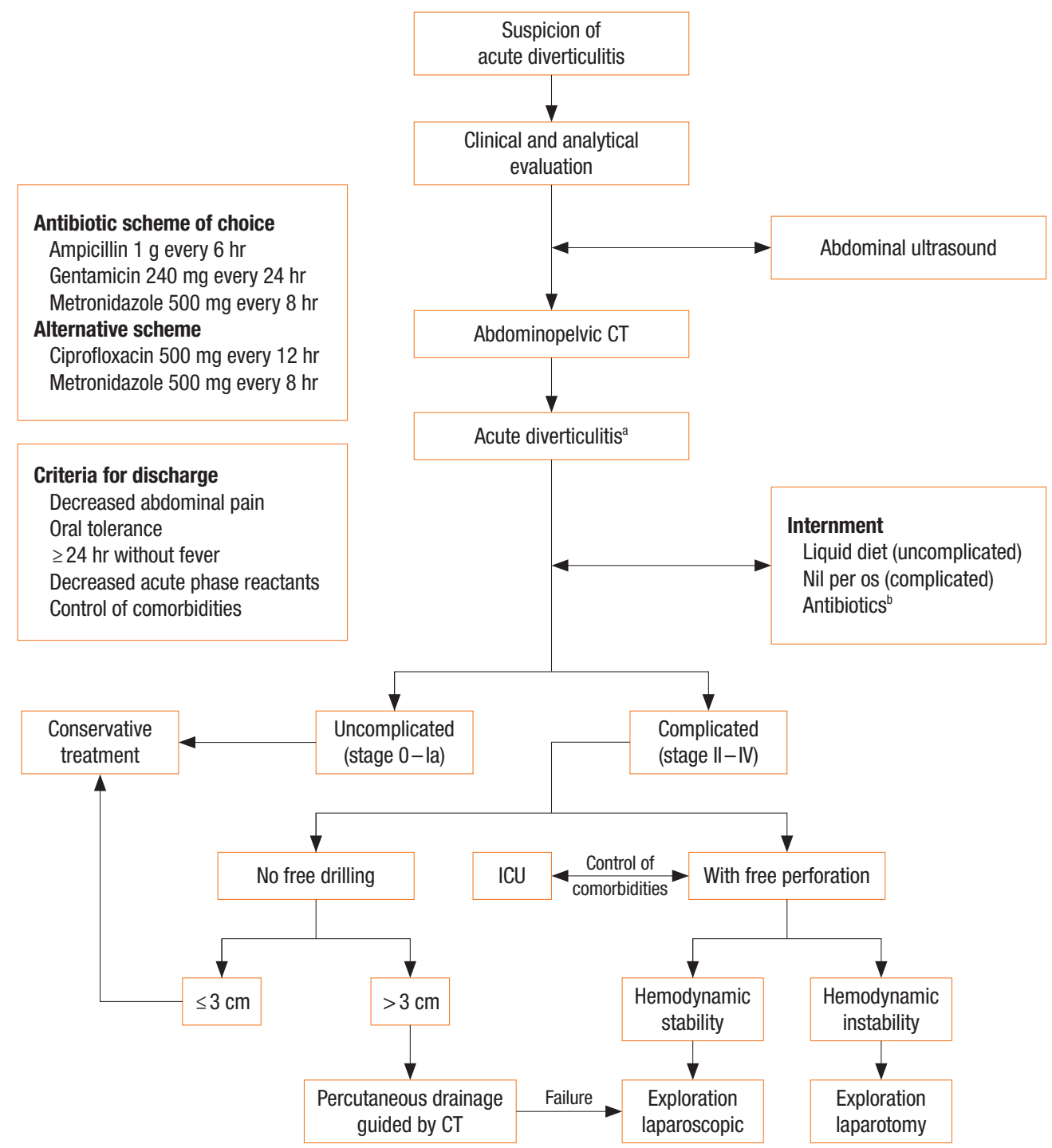

Fig. 1. Institutional algorithm for the diagnosis and treatment of acute diverticulitis. CT, computed tomography; ICU, intensive care unit. ${ }^{a}$ Modified Hinchey classification by Wasvary. ${ }^{\mathrm{b}}$ Antibiotics adjusted according to the renal function. 


\section{Study of variables}

The aspects analyzed were demographic variables (sex, age, and ethnic origin), body mass index (BMI), chronic comorbidities, Charlson comorbidity index (CCI), time of evolution of abdominal pain until admission to the emergency room, presence of peritoneal signs in the physical examination (abdominal palpation), body temperature, modified Hinchey classification, treatment (conservative or surgery), length of hospital stay, and symptom recurrence after discharge. Blood tests recorded the white cell count (WCC), the neutrophil-to-lymphocyte ratio (NLR), and the levels of C-reactive protein (CRP). The original diagnosis of the report made by the on-call radiologist was recorded, based on the initial abdominal ultrasound and computed tomography (CT).

\section{Definition of variables}

Modified Hinchey classification: The uncomplicated diverticulitis was defined as stage 0-Ia and complicated diverticulitis was defined as stage Ib-IV or associated with fistulas, stenosis, or colonic obstruction. $\mathrm{RD}$ is the colonic diverticulitis that spreads from the cecum to the transversal colon. LD is the colonic diverticulitis that spreads from the splenic flexure to the sigmoid colon. A body temperature of $\geq 38^{\circ} \mathrm{C}$ was defined as fever, and a WCC of $>10.0 \times 10^{9} / \mathrm{L}$ was considered leukocytosis.

\section{Treatment and follow-up}

Clinical decisions were made by a senior surgeon at the moment of diagnosis and the patients with $\mathrm{RD}$ were treated according to our institutional protocol for DD (Fig. 1). In cases where the initial diagnosis was uncertain or the clinical condition of the patient justified it, emergency surgery was performed.

Following discharge from the hospital, follow-up was performed by an experienced member of the General Surgery Service. We gathered the follow-up information from hospital records or by contacting patients or their relatives by phone.

\section{Statistical analysis}

The categorical variables were expressed as frequency (percentage), continuous variables as mean value \pm standard deviation or median (range). Mann-Whitney test was used to compare the continuous variables, and the chi-square test to compare categorical variables. A P-value of $<0.05$ was considered significant. For statistical analysis, IBM SPSS Statistics ver. 26 (IBM Corp., Armonk, NY, USA) and GraphPad ver. 7 (GraphPad Software, San Diego, CA, USA) were used.

\section{RESULTS}

\section{Demographic characteristics of patients}

A total of 410 patients were included; 3.9\% $(n=16)$ had $R D$, confirmed by images or during surgery (Table 1). Of these patients, $62.5 \%(n=10)$ were males and the mean age was $40.7 \pm 11.7$ years. Thirteen were Caucasian and three were Native American. This

Table 1. Clinical characteristics of patients with confirmed right-sided acute diverticulitis

\begin{tabular}{|c|c|c|c|c|c|c|c|c|c|c|}
\hline $\begin{array}{c}\text { Patient } \\
\text { No. }\end{array}$ & Age (yr) & Sex & Asian & $\begin{array}{c}\text { Duration of } \\
\text { symptoms (hr) }\end{array}$ & NLR & $\begin{array}{c}\text { WCC } \\
\left(\times 10^{9} / \mathrm{L}\right) \\
\end{array}$ & $\begin{array}{c}\text { CRP } \\
(\mathrm{mg} / \mathrm{dL})\end{array}$ & $\begin{array}{l}\text { Location of } \\
\text { diverticula }\end{array}$ & $\begin{array}{l}\text { Hinchey } \\
\text { stage }\end{array}$ & Treatment \\
\hline 1 & 30 & Male & No & 60 & 2.8 & 10 & 5 & Ascending colon & 0 & Conservative \\
\hline 3 & 49 & Male & No & 24 & 6.5 & 11.1 & 49 & Ascending colon & la & Conservative \\
\hline 4 & 34 & Female & No & 48 & 7 & 14 & 68 & Ascending colon & la & Conservative \\
\hline 7 & 26 & Female & No & 12 & 3.9 & 20 & 82 & Ascending colon & 0 & Surgery \\
\hline 8 & 40 & Male & No & 24 & 3.9 & 14.8 & 66 & Ascending colon & 0 & Surgery \\
\hline 9 & 45 & Male & No & 48 & 6.8 & 13.4 & 32 & Caecum & la & Conservative \\
\hline 10 & 43 & Male & No & 72 & 2.6 & 11.7 & 16 & Ascending colon & la & Conservative \\
\hline 14 & 60 & Male & No & 24 & 2 & 12 & 18 & Caecum & 0 & Conservative \\
\hline 15 & 18 & Female & $\mathrm{No}^{\mathrm{a}}$ & 48 & 2.5 & 10.7 & 6 & Caecum & la & Conservative \\
\hline 16 & 42 & Male & No & 120 & 8.2 & 13.9 & 198 & Hepatic flexure & la & Conservative \\
\hline
\end{tabular}

NLR, neutrophil-to-lymphocyte ratio; WCC, white cell count; CRP, C-reactive protein. aNative American. 
group was younger in comparison to the LD group ( $40.7 \pm 11.7$ years vs. $65.4 \pm 12.7$ years, $\mathrm{P}=0.001$ ). Also, they presented a lower BMI $\left(25.5 \pm 5.7 \mathrm{~kg} / \mathrm{m}^{2}\right.$ vs. $\left.29.3 \pm 4.2 \mathrm{~kg} / \mathrm{m}^{2}, \mathrm{P}=0.01\right)$, comorbidity rate $(18.8 \%$ vs. $33 \%, \mathrm{P}=0.01)$, CCI $(0.4$ vs. $2.8, \mathrm{P}=0.02)$ and a

Table 2. Differences between both groups of patients with acute diverticulitis

\begin{tabular}{|c|c|c|c|}
\hline Characteristic & Right-sided & Left-sided & P-value \\
\hline No. of patients & 16 & 394 & \\
\hline Sex & & & 0.95 \\
\hline Male & $10(62.5)$ & $231(58.6)$ & \\
\hline Female & $6(37.5)$ & $163(41.4)$ & \\
\hline Age (yr) & $40.7 \pm 11.7$ & $65.4 \pm 12.7$ & $0.001^{*}$ \\
\hline$<50$ & $13(81.3)$ & 40 (10.2) & \\
\hline $50-64$ & $3(18.8)$ & $171(43.4)$ & \\
\hline $65-79$ & $0(0)$ & $131(33.2)$ & \\
\hline$\geq 80$ & $0(0)$ & $52(13.2)$ & \\
\hline Body mass index $\left(\mathrm{kg} / \mathrm{m}^{2}\right)$ & $21.5 \pm 6.1$ & $27.3 \pm 6.4$ & $0.01^{*}$ \\
\hline Comorbidity & & & $0.01^{*}$ \\
\hline Arterial hypertension & $2(12.5)$ & $75(19)$ & \\
\hline Diabetes mellitus & $1(6.3)$ & $35(8.9)$ & \\
\hline Cardiovascular & $0(0)$ & $20(5.1)$ & \\
\hline Charlson comorbidity index & 0.3 & 2.0 & $0.02^{*}$ \\
\hline Onset of pain until admission (hr) & $47.3 \pm 10.2$ & $54.1 \pm 17.4$ & 0.05 \\
\hline Hinchey stage & & & $0.001^{*}$ \\
\hline 0 & $5(31.3)$ & $75(19.0)$ & \\
\hline la & $10(62.5)$ & $270(68.5)$ & \\
\hline $\mathrm{lb}$ & $1(6.3)$ & $19(4.8)$ & \\
\hline$\|$ & $0(0)$ & $11(2.8)$ & \\
\hline III & $0(0)$ & $13(3.4)$ & \\
\hline IV & $0(0)$ & $6(1.5)$ & \\
\hline Laboratory finding & & & 0.23 \\
\hline Leukocytes (×109/L) & $13.5 \pm 2.6$ & $12.1 \pm 3.4$ & \\
\hline $\mathrm{CRP}(\mathrm{mg} / \mathrm{dL})$ & $56.4 \pm 21.2$ & $62.2 \pm 29.9$ & \\
\hline NLR & $4.7 \pm 2.2$ & $5.6 \pm 2.4$ & \\
\hline Hospital stay (day) & $3.2 \pm 1.2$ & $5.3 \pm 3.4$ & $0.01^{*}$ \\
\hline Treatment & & & 0.34 \\
\hline Conservative, diet $+A B$ & $13(81.3)$ & $367(93.1)$ & \\
\hline Surgery & $3(18.8)$ & $16(4.1)$ & \\
\hline Percutaneous drainage $+A B$ & $0(0)$ & $11(2.8)$ & \\
\hline Follow-up (mo) & $22.8 \pm 8.4$ & $28.6 \pm 7.3$ & 0.32 \\
\hline Recurrence & $1(6.3)$ & 48 (12.2) & $0.001^{*}$ \\
\hline
\end{tabular}

Values are presented as number only, number $(\%)$, or mean \pm standard deviation. CRP, C-reactive protein; NLR, neutrophil-to-lymphocyte ratio; $A B$, antibiotics. *Significant associations $(P<0.05)$. lower severity of the stage according to the Hinchey classification $(\mathrm{P}=0.001)$ (Table 2). There were no significant differences between both groups in relation to sex $(\mathrm{P}=0.95)$. However, colonic diverticulitis was more common in males.

\section{Presentation}

All the patients with $\mathrm{RD}$ had abdominal pain, with an average length of 47.3 hours. However, there was no significant difference between both groups in relation to the length of symptoms until consultation $(\mathrm{P}=0.05)$. Only 1 patient with $\mathrm{RD}$ presented righthypochondrium pain with no radiation, associated with a palpable mass, simulating acute cholecystitis (Fig. 2). The main signs and symptoms are shown in Table 3 . The initial clinical suspicion of acute appendicitis (AA) was present in 12 patients with $\mathrm{RD}$.

According to the distribution of diverticula, $75.0 \%$ were located in the sigmoid colon, $21.1 \%$ in descending colon or splenic flexure, $2.7 \%$ in ascending colon or cecum, and $1.2 \%$ in hepatic flexure.
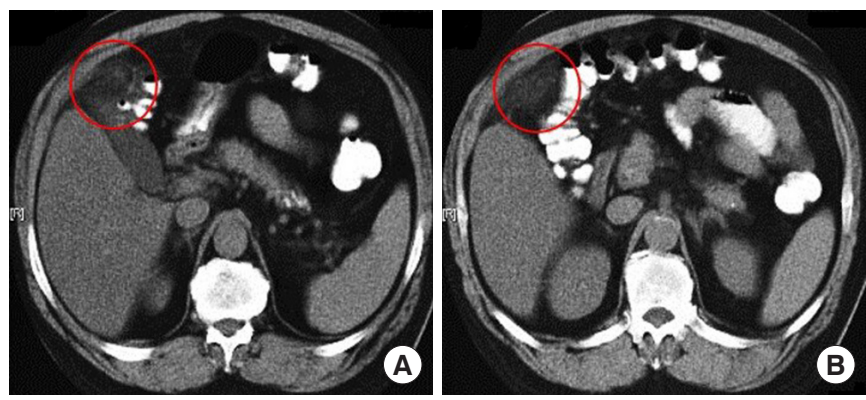

Fig. 2. Computed tomotraphy of the abdomen and pelvis showing (A) a severe inflammatory process of diverticular origin at the level of the hepatic flexure of the colon (red circle), and (B) pericolonic fat involvement and thickening of the colon wall (red circle).

Table 3. Presentation of signs and symptoms in right-sided acute diverticulitis

\begin{tabular}{lcc}
\hline Variable & Patient $(\mathrm{n}=16)$ & $95 \% \mathrm{Cl}$ \\
\hline Leukocytosis only & $15(93.8)$ & $82-100$ \\
Right iliac fossa pain & $15(93.8)$ & $82-100$ \\
Pain migration & $10(62.5)$ & $39-87$ \\
Nausea/vomiting & $7(43.8)$ & $20-68$ \\
Duration of pain $>48 \mathrm{hr}$ & $5(31.3)$ & $8-54$ \\
Diarrhoea & $4(25.0)$ & $4-46$ \\
Generalised abdominal pain & $4(25.0)$ & $4-46$ \\
Constipation & $3(18.8)$ & $0-38$ \\
Fever & $3(18.8)$ & $0-38$ \\
Leukocytosis + fever & $3(18.8)$ & $0-44$ \\
Palpable mass & $1(6.3)$ & $0-18$ \\
\hline
\end{tabular}

Values are presented as number (\%).

$\mathrm{Cl}$, confidence interval. 


\section{Laboratory findings}

Blood tests at the moment of consultation show leukocytosis in 93.8\% $(\mathrm{n}=15)$ of patients with $\mathrm{RD}$, with a mean value of $13.5 \times$ $10^{9} / \mathrm{L}$. Twelve patients $(75.0 \%)$ had a neutrophil count of $>70 \%$ with a mean value of $74.1 \%$. Seven $(43.8 \%)$ had a lymphocyte count of $<20 \%$ with a mean value of $18.4 \%$. The levels of CRP presented a mean value of $56.4 \mathrm{mg} / \mathrm{dL}$. We found a significant difference for NLR in the group of RD in relation to Hinchey stage, with a mean value of 3.1 for the stage O; 5.8 and 7.6 for the stages $\mathrm{Ia}$ and $\mathrm{Ib}$, respectively $(\mathrm{P}=0.01)$. However, there was no significant difference between both groups regarding the laboratory findings $(\mathrm{P}=0.23)$.

\section{Ultrasound findings}

All the patients with $\mathrm{RD}$ underwent abdominal ultrasound at the moment of emergency consultation. Pericolonic fat alteration was found in $75.0 \%(\mathrm{n}=12)$ and colon wall thickening was found in $68.8 \%(\mathrm{n}=11)$ of the cases. A diverticulum image was described in $25.0 \%(n=4)$ of radiological reports and it was not possible to visualize the cecal appendix in $68.8 \%(\mathrm{n}=11)$ of patients.

\section{Tomographic findings}

In 14 patients with $\mathrm{RD}$, the study was completed with abdominal CT. Pericolonic fat involvement and thickening of the colon wall were seen in all patients. Mesenteric fat involvement was mild in 71.4\% $(\mathrm{n}=10)$ and intense in $28.6 \%(\mathrm{n}=4)$; and in $18.8 \%(\mathrm{n}=3)$, a thickening of the right lateroconal fascia was observed. Colon wall thickening was mild $(3-5 \mathrm{~mm})$ in 4 patients, moderate (5-15 $\mathrm{mm}$ ) in 7 patients, and marked $(>15 \mathrm{~mm})$ in 3 patients. The diverticulum was seen in 13 cases (92.9\%) (Fig. 3) and 1 patient presented a pericolic abscess of $3 \mathrm{~cm}$, which received conservative treatment.

\section{Treatment and follow-up}

In the group of $\mathrm{RD}, 13$ patients were treated conservatively and in 3 , the diagnosis was erroneously confirmed during surgery. Of
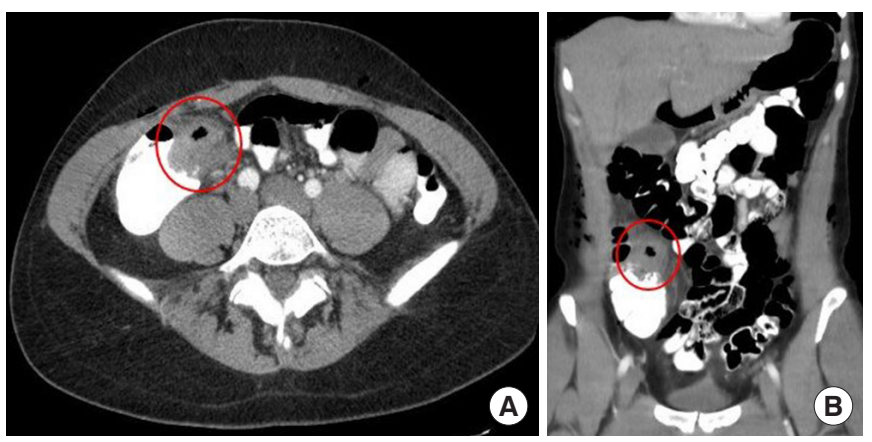

Fig. 3. Abdominal CT of a 35-year-old Caucasian female patient. (A) axial section, acute diverticulitis in the ascending colon. (B) coronal section, solitary diverticulum. The red circle illustrates the inflamed diverticulum. the patients who underwent surgery, 2 underwent only abdominal ultrasound, while the $3 \mathrm{rd}$ patient had a preoperative CT suggestive of cecal inflammation which affected the appendix. In these cases, the preoperative diagnosis was AA and the surgical approach was laparoscopic. In 2 patients, an appendectomy was not performed, because an inflammatory mass was detected on the external wall of the ascending colon without appendicular involvement; while in the 3rd case, the involvement of the appendiceal base was confirmed and prophylactic appendectomy was performed, with no findings of malignancy in the histopathological study.

After the surgery, the patients continued with intravenous antibiotics until the moment of hospital discharge, which was given when they presented clinical and analytical improvement. Two patients with $\mathrm{RD}$ were treated on an outpatient basis and the rest had a shorter hospital length of stay compared to the group of LD $(3.2 \pm 1.2$ days vs. $5.3 \pm 3.4$ days; $\mathrm{P}=0.01)$.

Following the hospital discharge, all the patients continued with oral antibiotics (amoxicillin and clavulanic acid $875 \mathrm{mg} / 125 \mathrm{mg}$ every 12 hours and metronidazole $500 \mathrm{mg}$ every 8 hours). The length of antibiotic treatment presented a mean of $11 \pm 3.5$ days. Only 2 patients were treated with the alternative antibiotic scheme due to allergy to penicillin.

With regard to the follow-up, the group with $\mathrm{RD}$ presented a mean of $22.8 \pm 8.4$ months. However, 2 patients were lost to follow-up. Colonoscopy was performed in a period greater than 8 weeks after the acute episode in 11 patients, detecting diverticula in the right colon in all of them. None of the cases presented any signs of diverticulitis.

The rate of recurrence was significantly lower in comparison to that of the LD group ( $6.3 \%$ vs. $12.2 \% ; \mathrm{P}=0.001)$, and it occurred in a single patient who was initially treated conservatively.

\section{DISCUSSION}

The Western countries are characterized by having a heterogeneous population that has migrated from the East, so the incidence of DD might increase considerably in the future [5]. However, no studies have demonstrated an alignment in the incidence between the immigrants and the native population.

Argentina is considered as a "country of immigration," in relation to the strong impact that various migratory flows have caused over the native composition of the population, especially of European origin, followed by American neighboring countries, and to a lesser extent Asian countries [9]. The 2010 census estimated that 3.4\% of people of Asian descent lived in Córdoba [10] and this could explain why our study has no Asian patients.

Reports have indicated that $\mathrm{RD}$ incidence in Asian population is $55 \%$ to $70 \%$, whereas in Caucasians is $1 \%$ to $2 \%$ [11]. In this series, the incidence in Caucasians was $3.2 \%$, being above that reported in the literature. Besides, it is more frequent in males, with a male to female ratio of 2.0:1 to 3.2:1; and it affects mainly young 
population between 32 to 53.1 years old $[11,12]$. Our findings were similar.

Pathologically, left-sided DD consists of pseudodiverticula and it has commonly been related to aging and a low dietary fiber intake, as risk factors [13]. On the other hand, the pathogenesis of DD is controversial and reports have indicated that they are congenital or "true" diverticula, with herniations that affect all the layers in the colonic wall and are not associated with aging [14]. In this cohort, the patients with $\mathrm{RD}$ were significantly younger than patients with $\mathrm{LD}$, a fact that would support the theory that $\mathrm{RD}$ has a congenital nature.

The anatomic distribution of diverticula seems to vary according to race. In Caucasians, $75 \%$ are located in the sigmoid colon, $11 \%$ in the splenic flexure or descending colon, $6 \%$ in the transversal colon, and only $8 \%$ in ascending colon or hepatic flexure [15]. This study showed that $21.1 \%$ were located in splenic flexure or descending colon and $3.2 \%$ in the right-sided colon.

On a clinical basis, it is difficult to distinguish $\mathrm{RD}$ from appendicitis, due to the fact that signs and symptoms are similar at the moment of presentation, especially in young patients [16]; which requires a differential diagnosis between these 2 pathologies to determine a therapeutic plan and avoid unnecessary surgeries, due to a misdiagnosis of AA [17]. In this cohort, AA was suspected in $75 \%$ of the cases. However, only 3 patients required surgery.

Currently, few studies have reported differences between $\mathrm{RD}$ and appendicitis. It has been described that the prevalence of pain migration was significantly higher in AA (39.2\%-82\%) compared to that of $\mathrm{RD}(15.4 \%-54 \%)[18,19]$. In this cohort, $63 \%$ of patients with $\mathrm{RD}$ presented abdominal pain migration, similar to that reported. Also, it could be confused with other diseases such as cholecystitis, gastritis, or peptic ulcer, although less frequently $[20,21]$. We found a patient with right hypochondrium pain who simulated cholecystitis, but without findings on biliary pathology ultrasound.

Among other differences existing with appendicitis, reports have indicated that the duration of abdominal pain is longer in $\mathrm{RD}(68.4 \pm 23.3$ hours vs. $29.8 \pm 20.2$ hours, $\mathrm{P}<0.01)$ [19]. In this work, the time interval from the onset of abdominal pain until admission was $47.3 \pm 10.2$ hours, similar to the information reported in the literature.

On the other hand, reports indicate a low incidence of nausea and vomiting in $\mathrm{RD}(8 \%-16 \%)$ compared to AA (32-72\%) [18], which differs from our findings, since in this study $44 \%$ of patients with $\mathrm{RD}$ presented nausea and vomiting.

With regard to fever, it was reported that its prevalence is not significantly different between AA and $\mathrm{RD}(14.4 \%$ vs. $15 \%, \mathrm{P}=$ 0.87 ) [18], similar to our results.

From the analytical approach, reports show that leukocytosis in $\mathrm{RD}$ is in $58 \%$ to $69.2 \%$; and in $\mathrm{AA}$, it is presented in $68.5 \%$ to $90 \%$ $[12,22]$. In this cohort, $94.0 \%$ of patients with $\mathrm{RD}$ presented a leukocyte count above $10.000 \times 10^{9} / \mathrm{L}$. However, the number of studies that have demonstrated its utility to differentiate both illnesses is limited, is this still a controversial topic.

In a recent study, we demonstrated the utility of NLR to predict complicated LD, with a cut-off point of $\geq 4.2$ as the best value of diagnostic approximation [23]. Similarly, in this cohort we found that NLR showed statistical significance in relation to the severity of Hinchey stage, validating its applicability as a reliable, noninvasive, and cost-effective marker in the early diagnosis of complicated DD.

After the clinical and analytical evaluation, radiological images are required to continue the assessment of patients with right lower quadrant pain. Reports indicate that the ultrasound performed by an experienced radiologist for $\mathrm{RD}$ diagnosis shows a sensitivity of $91.3 \%$ and a specificity of $99.8 \%$ [24], but other studies have not confirmed this information. Our diagnosis rate using the ultrasound scan was very low (25.0\%), similar to the results in other studies [12]. CT is another technique used in case of colonic diverticulitis suspicion, which presents a specificity of $90 \%$ to $95 \%$, but in some cases, it may establish a wrong diagnosis and confuse $\mathrm{RD}$ with an appendicular abscess, Crohn disease, epiploic infarction, or colon cancer [21]. CT has been reported to presents a preoperative diagnosis rate in $\mathrm{RD}$ of $78.4 \%$ to $83.3 \%[25,26]$. According to our institutional protocol, we completed the tomographic evaluation in $87.5 \%$ of our patients, with a preoperative diagnosis rate of $93 \%$.

There are no established guidelines for the treatment of $\mathrm{RD}$, and current recommendations commonly refer to the left-sided colon. It was shown that $\mathrm{RD}$ patients are less likely to have serious complications and therefore more likely to respond to conservative treatment with less need for emergency surgery and shorter length of hospital stay [5]. In our study, we found that the rate of complicated diverticulitis was significantly lower in the group of patients with $\mathrm{RD}(6.3 \%$ vs. $12.5 \%, \mathrm{P}=0.04)$. Furthermore, the conservative treatment was feasible in most patients due to the high rate of preoperative diagnosis.

The observed differences in disease severity between $\mathrm{RD}$ and $\mathrm{LD}$ may be explained by various factors. Inflammation in $\mathrm{RD}$ is more likely to be localized to a single diverticulum, while the inflammation in LD is commonly described as diffuse, involving multiple diverticula with wall thickening [27]. Anatomically most of the right colon is retroperitoneal which may limit the spread of inflammation, while the sigmoid colon, the most common site of $\mathrm{LD}$, is intraperitoneal which may result in the easier spread of inflammation [28].

Although it varies by investigator, the recurrence rate in $\mathrm{RD}$ after conservative treatments is shown to be approximately $3 \%$ to $15 \%$ [22]. During the follow-up, only 1 patient was detected recurrence but had no complications and a presented good evolution with the conservative treatment.

There is controversy as to the surgical treatment for $\mathrm{RD}$ found at the moment of surgery. Mainly 4 surgical strategies can be considered; diverticulectomy with appendectomy, ileocecal resection, 
right hemicolectomy, and prophylactic appendectomy [16]. From the patients who required surgery, 1 underwent prophylactic appendectomy for severe local inflammation, while in the other 2 patients, the exploration laparoscopic detected diverticulitis of the ascending colon that did not require appendectomy. However, appendectomy, alone, could be associated with an increase in the rate of recurrence and the need for a new surgery since this approach does not offer a definite treatment for RD [12]. None of the 3 patients operated on did present recurrences, nor complications during the follow-up, but it is difficult to establish the true recurrence rate in patients operated, due to the fact that in our experience we had a predominance of cases treated conservatively.

The limitations of our study were its retrospective design and that a small number of patients with $\mathrm{RD}$ treated in a single center in Córdoba, Argentina were recruited. However, the RD is considered a rare pathology in our environment. In addition, risk factors for diverticulitis, including eating habits, physical activity, and defecation habits, were not included in our research. Therefore, the results of our study cannot be generalized to the entire population.

In our environment, the incidence and complication rate of $\mathrm{RD}$ are lower compared to LD. Conservative treatment predominated in $\mathrm{RD}$. However, the evidence is very limited and further studies are required to provide robust data.

\section{CONFLICT OF INTEREST}

No potential conflict of interest relevant to this article was reported.

\section{REFERENCES}

1. Warner E, Crighton EJ, Moineddin R, Mamdani M, Upshur R. Fourteen-year study of hospital admissions for diverticular disease in Ontario. Can J Gastroenterol 2007;21:97-9.

2. Jacobs DO. Clinical practice. Diverticulitis. N Engl J Med 2007; 357:2057-66.

3. Peery AF. Management of colonic diverticulitis. BMJ 2021;372: n72.

4. Peery AF, Crockett SD, Murphy CC, Lund JL, Dellon ES, Williams JL, et al. Burden and cost of gastrointestinal, liver, and pancreatic diseases in the United States: update 2018. Gastroenterology 2019;156:254-72.

5. Hajibandeh S, Hajibandeh S, Smart NJ, Maw A. Meta-analysis of the demographic and prognostic significance of right-sided versus left-sided acute diverticulitis. Colorectal Dis 2020;22:1908-23.

6. Hawkins AT, Wise PE, Chan T, Lee JT, Glyn T, Wood V, et al. Diverticulitis: an update from the age old paradigm. Curr Probl Surg 2020;57:100862.

7. Sugihara K, Muto T, Morioka Y, Asano A, Yamamoto T. Diverticular disease of the colon in Japan. A review of 615 cases. Dis Colon Rectum 1984;27:531-7.
8. Cristaudo A, Pillay P, Naidu S. Caecal diverticulitis: presentation and management. Ann Med Surg (Lond) 2015;4:72-5.

9. Corach D. Mapa genético argentino. Encrucijadas 2010;(50):14-8.

10. Instituto Nacional de Estadística y Censos (2012) Censo Nacional de Población, Hogares y Viviendas 2010: Censo del Bicentenario.

11. Lee IK. Right colonic diverticulitis. J Korean Soc Coloproctol 2010;26:241-5.

12. Lee IK, Kim SH, Lee YS, Kim HJ, Lee SK, Kang WK, et al. Diverticulitis of the right colon: tips for preoperative diagnosis and treatment strategy. J Korean Soc Coloproctol 2007;23:223-31.

13. Manabe N, Haruma K, Nakajima A, Yamada M, Maruyama Y, Gushimiyagi $\mathrm{M}$, et al. Characteristics of colonic diverticulitis and factors associated with complications: a Japanese multicenter, retrospective, cross-sectional study. Dis Colon Rectum 2015;58: 1174-81.

14. Kim CN. What is the difference between right- and left-sided colonic diverticulitis? Ann Coloproctol 2016;32:206-7.

15. Peery AF, Keku TO, Martin CF, Eluri S, Runge T, Galanko JA, et al. Distribution and characteristics of colonic diverticula in a United States screening population. Clin Gastroenterol Hepatol 2016;14:980-5.

16. Yang HR, Huang HH, Wang YC, Hsieh CH, Chung PK, Jeng LB, et al. Management of right colon diverticulitis: a 10-year experience. World J Surg 2006;30:1929-34.

17. Song JH, Kim YW, Lee S, Do HH, Seo JS, Lee JH, et al. Clinical difference between acute appendicitis and acute right-sided colonic diverticulitis. Emerg Med Int 2020;2020:4947192.

18. Sasaki Y, Komatsu F, Kashima N, Sato T, Takemoto I, Kijima S, et al. Clinical differentiation of acute appendicitis and right colonic diverticulitis: a case-control study. World J Clin Cases 2019;7: 1393-402.

19. Shin JH, Son BH, Kim H. Clinically distinguishing between appendicitis and right-sided colonic diverticulitis at initial presentation. Yonsei Med J 2007;48:511-6.

20. Pugliese A, Viscido G, Picón-Molina H, Doniquian A, Palencia R. Colonic hepatic flexure diverticulitis. Rev Chil Cir 2013;65:50-3.

21. Ferrara F, Bollo J, Vanni LV, Targarona EM. Diagnosis and management of right colonic diverticular disease: a review. Cir Esp 2016;94:553-9.

22. Lee IK, Jung SE, Gorden DL, Lee YS, Jung DY, Oh ST, et al. The diagnostic criteria for right colonic diverticulitis: prospective evaluation of 100 patients. Int J Colorectal Dis 2008;23:1151-7.

23. Palacios Huatuco RM, Pantoja Pachajoa DA, Bruera N, Pinsak AE, Llahi F, Doniquian AM, et al. Neutrophil-to-lymphocyte ratio as a predictor of complicated acute diverticulitis: A retrospective cohort study. Ann Med Surg (Lond) 2021;63:102128.

24. Chou YH, Chiou HJ, Tiu CM, Chen JD, Hsu CC, Lee CH, et al. Sonography of acute right side colonic diverticulitis. Am J Surg 2001;181:122-7.

25. Shyung LR, Lin SC, Shih SC, Kao CR, Chou SY. Decision making in right-sided diverticulitis. World J Gastroenterol 2003;9:606-8.

26. Fang JF, Chen RJ, Lin BC, Hsu YB, Kao JL, Chen MF. Aggressive 


\section{Coloproctology René M. Palacios Huatuco, et al.}

resection is indicated for cecal diverticulitis. Am J Surg 2003;185: $135-40$.

27. Schneider LV, Millet I, Boulay-Coletta I, Taourel P, Loriau J, Zins M. Right colonic diverticulitis in Caucasians: presentation and outcomes versus left-sided disease. Abdom Radiol (NY) 2017;42:
810-7.

28. Mizuki A, Tatemichi M, Nakazawa A, Tsukada N, Nagata H, Kanai T. Changes in the clinical features and long-term outcomes of colonic diverticulitis in Japanese patients. Intern Med 2017;56: 2971-7. 